\title{
Vergelijking van twee California Mastitis Testen met de elektronische celgetalbepaling voor de detectie van intramammaire infecties in mengmelkstalen van melkvee
}

\author{
Comparison of two California Mastitis Tests with electronic cell count determination \\ for the detection of intramammary infections in composite milk samples \\ of dairy cows
}

\section{E. Biebaut, S. Piepers, D. Valckenier, S. De Vliegher}

Onderzoekseenheid Mastitis \& Melkkwaliteit, Vakgroep Voortplanting, Verloskunde en Bedrijfsdiergeneeskunde, Faculteit Diergeneeskunde, Universiteit Gent, Salisburylaan 133, 9820 Merelbeke, België

Evelien.Biebaut@UGent.be

AMENVATTING

Het celgetal van de melk is een indicator voor de aanwezigheid van een intramammaire infectie bij melkvee. Het doel van deze studie was om van 179 mengmelkstalen de resultaten van de elektronische celgetalbepaling via het Fossomatic ${ }^{\mathrm{TM}}$ toestel te vergelijken met deze van twee commerciële California Mastitis Testen (CMT) op basis van verslijming, al dan niet in combinatie met kleurverandering. De meest voorkomende major pathogenen bij bacteriologisch onderzoek waren Streptococcus uberis en Staphylococcus aureus en de vaakst geïsoleerde minor pathogenen waren de niet-aureus stafylokokken. Het celgetal geschat aan de hand van de CMT-testen kwam goed overeen met het elektronisch bepaalde celgetal bekomen met de Fossomatic ${ }^{\mathrm{TM}}$. De testkarakteristieken van beide CMT-testen waren vergelijkbaar, zowel onderling als met deze bekomen voor de elektronische celgetalbepaling. Op basis van de bevindingen kan geconcludeerd worden dat beide CMT-testen in de praktijk kunnen gebruikt worden om koeien met een intramammaire infectie veroorzaakt door major pathogenen te helpen detecteren.

\begin{abstract}
In dairy cattle, the milk somatic cell count is the most widely accepted indicator for the presence of intramammary infections. The aim of this study was to compare the results of the electronic cell counting on 179 composite milk samples with the results of two commercially available California Mastitis Tests (CMT), based on either the thickening of the solution or the thickening of the solution in combination with a color change.

The most frequently isolated major pathogens in the milk samples were Streptococcus uberis and Staphylococcus aureus and the minor pathogens most isolated were the non-aureus staphylococci. The somatic cell count estimated with the CMT-tests corresponded well with the one obtained with the Fossomatic $^{\mathrm{TM}}$. For both CMT-tests, the test characteristics were mutually comparable as well as with the one obtained with the electronic cell counting. Based on the findings, it can be concluded that both CMT-tests can be used in the field to help detect cows suffering from an intramammary infection due to major pathogens.
\end{abstract}

\section{INLEIDING}

Mastitis, een ontsteking van het uierweefsel, is meestal het gevolg van een intramammaire infectie (IMI) veroorzaakt door bacteriën. Wanneer bacteriën de uier binnendringen, reageert het lichaam met een ontstekingsreactie. Witte bloedcellen migreren vanuit de bloedbaan naar de uier met als doel de oorzakelijke kiem af te doden, waardoor het celgetal in de melk stijgt (Harmon, 2001). Er bestaan twee vormen 
van mastitis: klinische en subklinische mastitis. Klinische mastitis wordt gekenmerkt door macroscopisch waarneembare veranderingen van de melk, uier en/ of de koe en wordt derhalve gemakkelijk herkend door de melkveeveehouder tijdens het melken. Bij het gebruik van een automatisch melksysteem worden deze macroscopische wijzigingen niet waargenomen; de melkrobot geeft een melding bij een indicatie van mastitis op basis van afwijkingen van specifieke parameters. In geval van subklinische mastitis zijn deze afwijkingen niet zichtbaar waar te nemen. Bij deze vorm van mastitis stijgt enkel het celgetal van de melk. Het is dan ook belangrijk om koeien met een verhoogd celgetal snel te detecteren. Koeien met een recent verhoogd celgetal hebben immers tot vier keer meer kans op het doormaken van een klinische opflakkering (Van den Borne et al., 2011). Daarnaast produceren koeien met subklinische mastitis minder melk en zijn ze een potentiële bron van infectie voor de andere dieren in de stal (Rajala-Schultz et al., 1999; Halasa et al., 2009; Van den Borne et al., 2011; Zadoks et al., 2011).

Mastitis is nog steeds een van de meest voorkomende en duurste aandoeningen op een melkveebedrijf (Barkema et al., 1999; Piepers et al., 2007; Aghamohammadi et al., 2018). Mastitis kost gemiddeld 140 euro per koe per jaar (Huijps et al., 2008). In 2017 telde Vlaanderen 322.978 melkkoeien (Vilt, Vlaams infocentrum land- en tuinbouw) en kostte mastitis de Vlaamse melkveehouders dus ruw geschat meer dan 45 miljoen euro. Hoewel vooral de kosten te wijten aan klinische mastitis aanzienlijk zijn, mogen ook deze te wijten aan subklinische mastitis niet onderschat worden. Subklinische mastitis kost de veehouder per aanwezige koe tussen 17 en 198 euro per jaar (Hogeveen et al., 2011; Heikkilä et al., 2012).

De eenvoudigste manier om koeien met subklinische mastitis te detecteren is door het regelmatig bepalen van het celgetal via de Melk Productie Registratie (MPR, CRV, Sint-Denijs-Westrem, België), waarbij concreet elke vier tot zes weken het celgetal van elke individuele koe elektronisch wordt gekwantificeerd middels toestellen met een hoge capaciteit in een professioneel labo. Voor Vlaanderen gebeuren de analyses van de MPR-stalen in het labo van het Melkcontrolecentrum Vlaanderen (MCC) aan de hand van een Fossomatic ${ }^{\mathrm{TM}}$ (Foss Electric, Hillerød, Denemarken) toestel. Een van de belangrijkste redenen waarom niet alle Vlaamse melkveehouders deelnemen aan de MPR is de kostprijs. De investering voor deelname bedraagt gemiddeld 25 euro per koe per jaar (CRV, Coöperatieve Rundveeverbetering).

Daarentegen is de California Mastitis Test (CMTtest) een goedkope en snelle test voor de celgetalbepaling die door de melkveehouder zelf in de melkput uitgevoerd kan worden. Een gelijke hoeveelheid melk en CMT-reagens, een zeepoplossing, worden samen gevoegd. Het CMT-reagens bevat natriumhydroxide, waardoor de celwand gelyseerd wordt, het DNA vrijkomt en de oplossing verslijmt. Hoe meer cellen er in de melk aanwezig zijn, des te slijmiger het mengsel wordt. Er bestaan twee types CMT-testen: één waarbij het celgetal wordt geschat op basis van verslijming en één waarbij het celgetal wordt geschat op basis van een combinatie van verslijming en kleurverandering. De normale $\mathrm{pH}$ van melk bedraagt 6,7 ; bij mastitis wordt de melk echter alkalischer, met een $\mathrm{pH}$ van 7,4 (Blowey en Edmondson, 2010). In het CMT-reagens is een $\mathrm{pH}$-indicator aanwezig. Deze is verantwoordelijk voor de kleurverandering ten gevolge van het $\mathrm{pH}$ verschil tussen normale melk en melk aangetast door mastitis. De nadelen van de CMT-test zijn dat er pas een duidelijk zichtbare reactie optreedt vanaf 400.000 cellen $/ \mathrm{ml}$, dat de interpretatie subjectief is en dat men slechts een ruwe indicatie van het celgetal bekomt (Hogan et al., 1999; Kivaria et al., 2007).

Het doel van deze studie was om de resultaten van de klassieke, elektronische celgetalbepaling via het Fossomatic $^{\mathrm{TM}}$-toestel te vergelijken met de resultaten bekomen via beide commercieel beschikbare CMTtesten. Er werd nagegaan of de uitslag van beide CMT-testen overeenkwam met het resultaat bekomen met de Fossomatic ${ }^{\mathrm{TM}}$. Daarnaast werden de testkarakteristieken voor de detectie van een IMI met een minor en/of major pathogeen en de detectie van een IMI met enkel een major pathogeen voor beide testen berekend en vergeleken met deze voor de elektronische celgetalbepaling.

\section{MATERIAAL EN METHODEN}

\section{Selectie bedrijven en koeien}

Er werden achttien willekeurig geselecteerde, commerciële melkveebedrijven in de studie opgenomen. Inclusiecriteria waren deelname aan de vier- vijf- of zeswekelijkse MPR (CRV, Sint-Denijs-Westrem, België), uitgerust zijn met een conventionele melkinstallatie en minstens vijftig dieren in lactatie hebben. De gemiddelde 305-dagenproductie bedroeg $9.688 \mathrm{~kg}$ en het gemiddelde bedrijfscelgetal, bekomen door een gemiddelde te nemen van het celgetal van alle koeien die deelnamen aan de MPR, was 195.889 cellen/ml met een minimum van 84.000 en een maximum van 396.000 cellen $/ \mathrm{ml}$.

Per bedrijf werden tien koeien geselecteerd voor de staalname van melk op basis van hun individuele koecelgetal op de meest recente MPR-uitslag vóór het bedrijfsbezoek. Op één bedrijf werden er slechts negen koeien in plaats van tien bemonsterd. De dieren werden als volgt geselecteerd: eerst werden dieren gekozen met een chronisch verhoogd celgetal (minstens twee opeenvolgende MPR-uitslagen met verhoogd celgetal), gevolgd door dieren met een nieuw verhoogd celgetal (vorige MPR-uitslag met laag celgetal), en indien nodig aangevuld met koeien met een laag celgetal. Een verhoogd celgetal werd gedefinieerd als $>250.000$ cellen $/ \mathrm{ml}$ voor koeien met $\geq$ twee lactaties en $>150.000$ cellen $/ \mathrm{ml}$ voor eerstekalfsdieren. 
Tabel 1. Scorekaart op basis van de zichtbare verandering voor de twee commercieel beschikbare California Mastitis Testen en de onder- en bovengrenzen van het celgetal per score voorgesteld door de producenten.

\begin{tabular}{|c|c|c|}
\hline Score & $\begin{array}{c}\text { CMT-testverslijming } \\
\text { Waarneming } \\
\text { [Celgetal }(\mathbf{x 1 . 0 0 0} \text { cellen } / \mathrm{ml})]\end{array}$ & $\begin{array}{c}\text { CMT-testverkleuring } \\
\text { Waarneming } \\
\text { [Celgetal }(\mathbf{x} 1.000 \text { cellen } / \mathrm{ml})]\end{array}$ \\
\hline 0 & $\begin{array}{l}\text { Vloeibaar, geen gel } \\
\qquad[0-200]\end{array}$ & $\begin{array}{l}\text { Vloeibaar, geen gel of kleur verandering } \\
\qquad[0-200]\end{array}$ \\
\hline 1 & $\begin{array}{l}\text { Sporen van gel die verdwijnen } \\
\text { na } 10 \text { seconden } \\
{[150-500]}\end{array}$ & $\begin{array}{l}\text { Sporen van gel, die verdwijnen } \\
\text { na } 10 \text { seconden } \\
{[150-500]}\end{array}$ \\
\hline 2 & $\begin{array}{c}\text { Lichte gel } \\
{[400-1.500]}\end{array}$ & $\begin{array}{l}\text { Lichte gel, gaat niet weg } \\
\qquad[400-1.000]\end{array}$ \\
\hline 3 & $\begin{array}{l}\text { Duidelijke gel } \\
{[800-5.000]}\end{array}$ & $\begin{array}{l}\text { Gel, kleverig, plakt aan het schaaltje } \\
{[800-5.000]}\end{array}$ \\
\hline 4 & $\begin{array}{l}\text { Sterke gel } \\
{[>5.000]}\end{array}$ & $\begin{array}{l}\text { Sterke gel met paarsverkleuring } \\
\qquad[>5.000]\end{array}$ \\
\hline
\end{tabular}

\section{Staalname en staalverwerking}

Tijdens de avondmelkbeurt werd, per vooraf geselecteerde koe, van elk kwartier een steriel melkstaal genomen volgens de procedure voorgesteld door de National Mastitis Council (NMC, 2004) in een cylindrische melkbuis (30 ml; Novolab, Geraardsbergen, België). Samengevat werd eerst het macroscopisch zichtbare vuil van de speen verwijderd met een individuele, droge, papieren wegwerpdoek. Daarna werden uit elke speen de eerste drie stralen melk weggemolken en werd de speentop zorgvuldig ontsmet met een kompres samengesteld uit absorberend gaas (Sterilux, Hartmann, Saintes, België) gedrenkt in een 96\%-alcoholoplossing (Ethanol VWR 96\%, Nerum, Heusden, België). Hierbij werd een vaste volgorde gehanteerd, waarbij eerst de spenen het verst van de staalnemer werden ontsmet. Tijdens de staalname zelf werd de cylindrische melkbuis voorzichtig geopend zonder hierbij de binnenkant van de dop aan te raken, onmiddellijk omgekeerd zodat er geen contaminatie kon optreden, voor minstens twee derden van het totale volume gevuld met melk en terug steriel gesloten. Bij de staalname zelf werd eerst een melkstaal genomen van de kwartieren het dichtst bij de staalnemer.

Alle melkstalen werden onmiddellijk na de staalname getransporteerd naar het laboratorium van de Onderzoekseenheid Mastitis en Melkkwaliteit (Vakgroep Voortplanting, Verloskunde en Bedrijfsdiergeneeskunde, Faculteit Diergeneeskunde, Universiteit Gent). In het laboratorium werden in de laminaire flowkast per bemonsterd dier van de vier individuele kwartiermelkstalen op steriele wijze twee mengstalen gemaakt. Eerst werd elk kwartiermelkstaal drie keer zacht op en neer geschud. Daarna werd van elk kwartiermelkstaal met een pipetboy en een steriele $10 \mathrm{ml}$ - pipet $9 \mathrm{ml}$ melk in een steriel recipiënt (Melkcontrolecentrum Vlaanderen, Lier, België) overgebracht en nog eens $3 \mathrm{ml}$ melk per kwartiermelkstaal in een nietsteriel recipiënt. Het resultaat per koe was één steriel staal van $36 \mathrm{ml}$ mengmelk voor de uitvoering van het bacteriologisch onderzoek en voor de bepaling van het koecelgetal (Fossomatic ${ }^{\mathrm{TM}}$ 5000, Foss Electric, Hillerød, Denemarken) uitgevoerd door het Melkcontrolecentrum Vlaanderen (MCC Vlaanderen) en één niet-steriel staal van $12 \mathrm{ml}$ mengmelk voor de uitvoering van beide CMT-testen. De stalen voor MCC Vlaanderen werden in de koelkast $\left(6,2^{\circ} \mathrm{C}\right)$ bewaard tot ophaling diezelfde nacht. De mengmelkstalen voor de uitvoering van de twee CMT-testen werden ofwel onmiddellijk geanalyseerd ofwel maximum 24 uur bewaard in de koelkast voorafgaand aan hun analyse.

\section{Laboratoriumanalyses}

\section{Bacteriologisch onderzoek}

In het labo van MCC Vlaanderen werd $10 \mu \mathrm{l}$ melk van elk mengmelkstaal uitgeënt op Esculin Sheep Blood agar (Oxoid, Aalst, België) en MacConkey agar (Oxoid, Aalst, België) en gedurende 24 tot 48 uur aeroob geïncubeerd bij $37^{\circ} \mathrm{C}$. Daarna werd elke fenotypisch verschillende kolonie geteld. Een dier werd als geïnfecteerd beschouwd indien minstens één kolonie van minstens één kiem kon worden geteld $(\geq$ $100 \mathrm{CFU} / \mathrm{ml})$. In het andere geval werden de dieren als niet-geïnfecteerd beschouwd. Melkstalen waarbij meer dan drie fenotypisch verschillende kiemen werden geïdentificeerd, werden als polybacterieel of gecontamineerd beschouwd. Fenotypische testen werden gebruikt om de verschillende kolonies van de cultuurpositieve stalen te differentiëren volgens de richt- 
lijnen uitgegeven door de National Mastitis Council (Hogan et al., 1999). Dieren met een mengmelkstaal dat cultuurpositief werd bevonden voor niet-aureus stafylokokken (NAS), Corynebacterium bovis en Bacillus spp., werden als geïnfecteerd met minor pathogenen beschouwd. Dieren met een mengmelkstaal dat cultuurpositief werd bevonden voor Staphylococcus aureus, Streptococcus uberis, esculine-positieve kokken, Streptococcus dysgalactiae, Streptococcus agalactiae, Escherichia coli, Klebsiella spp. en Pasteurella spp., werden als geïnfecteerd met major pathogenen beschouwd (ongeacht of er een eventuele co-infectie met een minor pathogeen aanwezig was).

\section{Individuele celgetalbepaling}

Het celgetal van de 36 ml-mengmelkstalen werd (in enkelvoud) elektronisch gekwantificeerd (Fossomatic ${ }^{\text {TM }}$ 5000, Foss Electric, Hillerød, Denemarken) in het labo van MCC Vlaanderen. De aspiratie van de rauwe melk in de cassette van het toestel gebeurt automatisch, waarna het aantal cellen in het mengmelkstaal gemeten wordt door middel van flowcytometrie.

\section{California Mastitis Test}

Op elk 12 ml-mengmelkstaal werden twee verschillende types CMT-testen uitgevoerd: één waarbij het celgetal wordt geschat op basis van de graad van verslijming (DeLaval, Tumba, Zweden), verder vermeld als CMT-testverslijming, en één waarbij het celgetal wordt geschat op basis van de graad van verslijming in combinatie met een kleurverandering (Keno $^{\text {TM}}$-test,CID LINES, Ieper, België), verder vermeld als CMT-testverkleuring. Eerst werden deze mengmelkstalen voorzichtig op en neer geschud. Daarna werd een gelijke hoeveelheid (3 ml) mengmelk en CMT-reagens samengevoegd in een kwartiercirkel van een vierkwartierenschaal en zachtjes rondgedraaid gedurende vijftien tot twintig seconden, waarna het resultaat werd afgelezen. Elk mengmelkstaal kreeg een score van 0 tot en met 4 toegekend op basis van de waargenomen verandering in de verslijming (CMT-testverslijming) of verslijming en kleur (CMT-testverkleuring). Elke score werd afgelijnd door een celgetal als onder- en bovengrens; deze grenzen werden vastgelegd op basis van de richtlijnen opgesteld door de CMT-producenten (Tabel 1). Na elke CMT-test werd de vierkwartierenschaal grondig uitgespoeld, schoongemaakt en afgedroogd met een individuele papieren wegwerpdoek.

\section{STATISTISCHE ANALYSE}

\section{Vergelijking California Mastitis Test en elektroni- sche celgetalbepaling}

Eerst werd per CMT-score het gemiddelde elektronische celgetal berekend en vergeleken met de richtlijnen uitgegeven door de producenten van beide CMT-testen. Daarnaast werd de CMT-score van de mengmelkstalen vergeleken met de elektronische celgetalbepaling, die als gouden standaard werd beschouwd. De bekomen resultaten werden onderverdeeld in vier verschillende categorieën zoals beschreven door Boyen et al. (2010): (1) de schatting aan de hand van de CMT-test werd als 'overeenstemming' beschouwd als het elektronisch bepaalde celgetal zich tussen de grenzen van de bekomen CMT-score bevond, (2) de schatting aan de hand van de CMT-test werd als 'kleine fout' beschouwd als het elektronisch bepaalde celgetal lager was dan de ondergrens van de bekomen CMT-score, (3) de schatting aan de hand van de CMT-test werd als 'grote fout' beschouwd als het elektronisch bepaalde celgetal hoger was dan de bovengrens van de bekomen CMT-score en (4) de schatting aan de hand van de CMT-test werd als 'zeer grote fout' beschouwd als het elektronisch bepaalde celgetal $>800.000$ cellen $/ \mathrm{ml}$ bedroeg en het

Tabel 2. Distributie van de gemengde infecties (minstens twee fenotypisch verschillende mastitiskiemen in hetzelfde mengmelkstaal).

\begin{tabular}{|c|c|c|c|c|c|}
\hline Eerste kiem & Tweede kiem & Aantal stalen & Eerste kiem & Tweede kiem & Aantal stalen \\
\hline \multirow[t]{10}{*}{ NAS } & S. uberis & 10 & C. bovis & Aerococcus spp. & 3 \\
\hline & C. bovis & 9 & & Bacillus & 2 \\
\hline & Aerococcus spp. & 7 & & E. coli & 1 \\
\hline & Enterococcus spp. & 3 & & S. aureus & 1 \\
\hline & Bacillus spp. & 2 & & S. uberis & 1 \\
\hline & S. agalactiae & 2 & S. aureus & polybacterieel & 4 \\
\hline & E. coli & 1 & & Bacillus spp. & 1 \\
\hline & Klebsiella oxytoca & 1 & S. dysgalactiae & S. uberis & 2 \\
\hline & S. aureus & 1 & & polybacterieel & 1 \\
\hline & S. dysgalactiae & 1 & Aerococcus spp. & Bacillus spp. & 1 \\
\hline Enterococcus spp. & Bacillus spp. & 1 & & T. pyogenes & 1 \\
\hline
\end{tabular}

NAS (niet-aureus stafylokokken); spp. (species); S. uberis (Streptococcus uberis); C. bovis (Corynebacterium bovis); S. agalactiae (Streptococcus agalactiae); E. coli (Escherichia coli); S. aureus (Staphylococcus aureus); S. dysgalactiae (Streptococcus dysgalactiae); T. pyogenes (Trueperella pyogenes). 
CMT-resultaat als negatief werd beoordeeld. Er werd bewust gekozen om een onderschatting van het celgetal met de CMT-test ten opzichte van het elektronisch bepaalde celgetal als een grotere fout te beschouwen dan een overschatting van het celgetal door de CMTtest. Er werd aangenomen dat de extra kosten die gepaard kunnen gaan met het nemen van een melkstaal voor bacteriologisch onderzoek van een koe met een laag celgetal niet opwegen tegen de potentiële verliezen die gepaard kunnen gaan met het niet of laattijdig identificeren van koeien met een verhoogd celgetal (Van den Borne et al., 2011). Immers, wanneer via de CMT-test het celgetal hoger wordt geschat dan in werkelijkheid het geval is, wordt op basis van de positieve CMT-score beslist om een staal te nemen voor bacteriologisch onderzoek terwijl dit misschien niet nodig was geweest. Echter, wanneer het celgetal via de CMT-test lager wordt geschat dan in werkelijkheid het geval is, zal op basis van de negatieve CMT-score vermoedelijk geen actie worden opgenomen, terwijl de koe in werkelijkheid wel een verhoogd celgetal heeft en haar uier (kwartier) potentieel met een major pathogeen geïnfecteerd is.

\section{Testkarakteristieken van de California Mastitis Test en de elektronische celgetalbepaling}

Zowel voor de elektronische celgetalbepaling als voor beide CMT-testen werden de testkarakteristieken en bijbehorende 95\%-betrouwbaarheidsintervallen ( $95 \%$ BI) berekend voor de detectie van IMI. De sensitiviteit (Se) van een test geeft de verhouding weer tussen het aantal koeien dat als geïnfecteerd wordt beschouwd door de test en het totaal aantal koeien met een cultuurpositief melkstaal. De specificiteit $(\mathrm{Sp})$ geeft de verhouding weer tussen het aantal koeien dat als niet-geïnfecteerd wordt beschouwd door de test en het totaal aantal koeien waarvan het melkstaal als cultuurnegatief wordt bevonden. De positief voorspellende waarde (PVW) geeft de verhouding weer tussen het aantal koeien met een cultuurpositief melkstaal en het totaal aantal koeien dat op basis van de test als geïnfecteerd wordt beschouwd. De negatief voorspellende waarde (NVW) geeft de verhouding weer van het aantal koeien met een cultuurnegatief melkstaal en het totaal aantal koeien dat als niet-geïnfecteerd wordt beschouwd door de test (Dewulf, 2017). Om de testkarakteristieken van de elektronische celgetalbepaling en de beide CMT-testen te bepalen, werd een afkapwaarde (“cut-off") van respectievelijk $\geq 200.000$ cellen $/ \mathrm{ml}$ en $\geq 1$ gebruikt. De cut-off van 200.000 cellen $/ \mathrm{ml}$ is het gemiddelde van de cut-off van 250.000 cellen $/ \mathrm{ml}$ voor een multipare koe en 150.000 cellen/ $\mathrm{ml}$ voor een eerstekalfsdier. De testkarakteristieken werden berekend voor de detectie van IMI zowel met een minor en/of major pathogeen als met enkel major pathogenen.

\section{RESULTATEN}

\section{Bacteriologisch onderzoek}

Er werden 179 mengmelkstalen onderzocht op de aanwezigheid van mastitispathogenen. Uit 18 mengmelkstalen $(10,1 \%)$ kon geen enkele kiem worden geïsoleerd (cultuurnegatief), uit 77 mengmelkstalen $(43,0 \%)$ werd één kiemsoort geïsoleerd, uit 56 mengmelkstalen $(31,3 \%)$ werden één tot drie verschillende kiemsoorten geïsoleerd (gemengd resultaat), en 28 mengmelkstalen $(15,6 \%)$ werden als polybacterieel beschouwd (Figuur 1).

Van de 77 mengmelkstalen waaruit een reincultuur van één specifieke kiemsoort werd geïsoleerd waren er vijftig cultuurpositief voor een minor pathogeen en 27 cultuurpositief voor een major pathogeen. In Tabel 2 wordt een overzicht gegeven van de verschillende combinaties van de mengmelkstalen waaruit één tot drie verschillende kiemen werden geïsoleerd.

De heterogene groep van de NAS werd het vaakst geïsoleerd $(\mathrm{n}=70)$, gevolgd door Corynebacterium bovis $(\mathrm{n}=27)$, Streptococcus uberis $(\mathrm{n}=23)$ en Staphylococcus aureus $(\mathrm{n}=17)$.

\section{Vergelijking California Mastitis Test met elektro- nische celgetalbepaling}

Van alle mengmelkstalen werd het celgetal elektronisch bepaald. In totaal hadden 105 koeien een celgetal tussen 0 cellen $/ \mathrm{ml}$ en 200.000 cellen $/ \mathrm{ml}$, 42 koeien tussen $>200.000$ cellen $/ \mathrm{ml}$ en 500.000 cellen $/ \mathrm{ml}, 21$ koeien tussen $>500.000$ cellen $/ \mathrm{ml}$ en 1.000 .000 cellen $/ \mathrm{ml}, 9$ koeien tussen $>1.000 .000$ cellen $/ \mathrm{ml}$ en 5.000 .000 cellen $/ \mathrm{ml}$ en 2 koeien een celgetal $>5.000 .000$ cellen $/ \mathrm{ml}$ (Figuur 2).

Per CMT-score werd het gemiddelde elektronisch bepaalde celgetal berekend. Voor de CMT-testverslijming waren de gemiddelde celgetalwaarden per CMT-
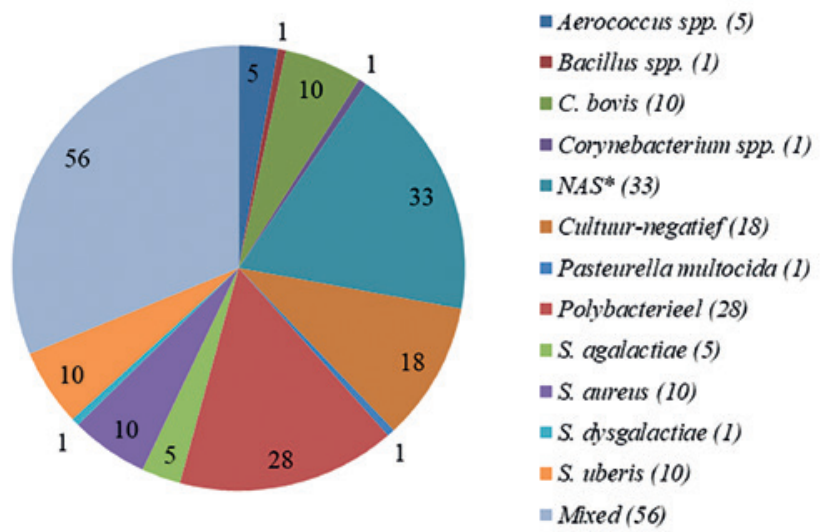

Figuur 1. Distributie van de geïsoleerde mastitiskiemen uit het bacteriologisch onderzoek van de mengmelkstalen (n=179). *NAS (niet-aureus stafylokokken). 
Tabel 3A. Gemiddelde elektronisch bepaalde celgetal bekomen met de Fossomatic ${ }^{\mathrm{TM}}$ (FOSS) voor alle melkstalen met eenzelfde score met de California Mastitis Testverslijming (CMT-test) vergeleken met de richtlijnen voorgesteld door de producent.

\begin{tabular}{ccccc}
\hline CMT-score & $\begin{array}{c}\text { Aantal } \\
\text { stalen }\end{array}$ & $\begin{array}{c}\text { Verwacht celgetal } \\
\mathbf{( x 1 0 0 0} \text { cellen/ml) }\end{array}$ & $\begin{array}{c}\text { Gemiddeld FOSS celgetal } \\
(\mathbf{x} 1000 \text { cellen/ml) }\end{array}$ & $\begin{array}{c}\text { Laagste en hoogste celgetal } \\
(\mathbf{x 1 0 0 0} \text { cellen/ml) }\end{array}$ \\
\hline 0 & 105 & $0-200$ & 110 & $10-454$ \\
1 & 44 & $150-500$ & 542 & $79-7.895$ \\
2 & 26 & $400-1.500$ & 1.176 & $182-7.616$ \\
3 & 4 & $800-5.000$ & $*$ & $349-2.540$ \\
4 & 0 & $>5.000$ & $*$ & $*$ \\
\hline
\end{tabular}

* Geen enkel melkstaal kreeg CMT-score 4

Tabel 3B. Gemiddelde elektronisch bepaalde celgetal bekomen met de Fossomatic ${ }^{\mathrm{TM}}$ (FOSS) voor alle mengmelkstalen met eenzelfde score met de California Mastitis Testverkleuring (CMT-test) vergeleken met de richtlijnen voorgesteld door de producent.

\begin{tabular}{ccccc}
\hline CMT-score & $\begin{array}{c}\text { Aantal } \\
\text { stalen }\end{array}$ & $\begin{array}{c}\text { Verwacht celgetal } \\
\mathbf{( x 1 0 0 0} \text { cellen/ml) }\end{array}$ & $\begin{array}{c}\text { Gemiddeld FOSS celgetal } \\
\mathbf{( x 1 0 0 0} \text { cellen/ml) }\end{array}$ & $\begin{array}{c}\text { Laagste en hoogste celgetal } \\
\mathbf{( x 1 0 0 0} \text { cellen/ml) }\end{array}$ \\
\hline 0 & 97 & $0-200$ & 104 & $10-749$ \\
1 & 45 & $150-500$ & 496 & $79-7.895$ \\
2 & 29 & $400-1.000$ & 778 & $191-3.696$ \\
3 & 8 & $800-5.000$ & 1.952 & $349-7.616$ \\
4 & 0 & $>5.000$ & $* *$ & \\
\hline
\end{tabular}

* Geen enkel melkstaal kreeg CMT-score 4

score: 110.000 (CMT-score 0), 542.000 (CMT-score 1), 1.176 .000 (CMT-score 2) en 1.153 .000 cellen $/ \mathrm{ml}$ (CMT-score 3) (Tabel 3A). Voor de CMT-testverkleuring waren de gemiddelde celgetalwaarden per CMTscore: 104.000 (CMT-score 0), 496.000 (CMT-score 1), 778.000 (CMT-score 2) en 1.952 .000 cellen $/ \mathrm{ml}$ (CMT-score 3) (Tabel 3B). Op één uitzondering na lagen voor beide CMT-testen de gemiddelde waarden van het elektronisch gemeten celgetal voor alle CMTscores tussen de onder- en bovengrenzen voorgesteld door de respectievelijke producenten. Enkel voor de mengmelkstalen met een CMT-score 1 bij de CMTtestverslijming overschreed het gemiddelde celgetal van 542.136 cellen/ml de bovengrens van 500.000 cellen $/ \mathrm{ml}$.

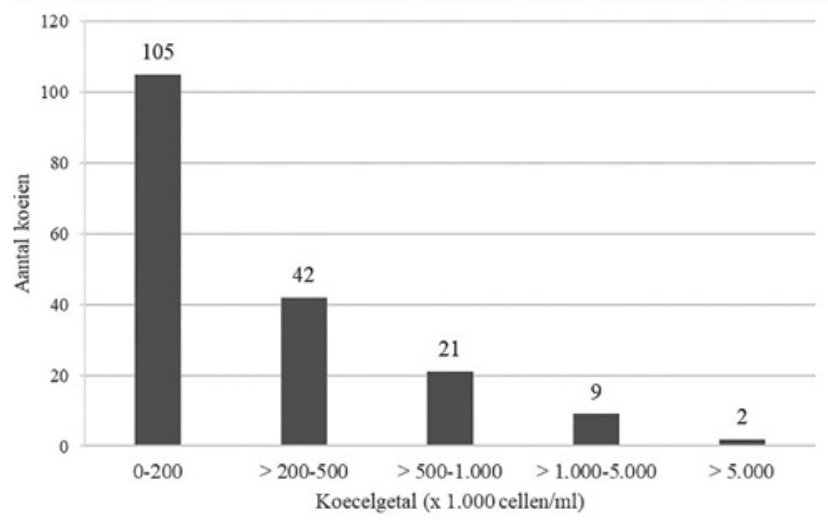

Figuur 2. Overzicht van het aantal koeien onderverdeeld op basis van hun koecelgetal op elektronische wijze gemeten met de Fossomatic ${ }^{\mathrm{TM}}$.
Van alle CMT-scores bekomen met de CMT-testverslijming werden er $148(82,7 \%)$ als 'overeenstemming' beschouwd, terwijl dit er $150(83,8 \%)$ waren na analyse met de CMT-testverkleuring. Daarnaast werden $12(6,7 \%)$ en $14(7,8 \%)$ van de CMT-scores bekomen met de CMT-testverslijming en de CMT-testverkleuring, respectievelijk, als 'kleine fout' beschouwd. Het aantal CMT-scores dat als een 'grote fout' werd beschouwd, bedroeg 19 (10,6\%) met de CMT-testverslijming en $15(8,4 \%)$ met de CMT-testverkleuring. Voor geen van beide testen werd een CMT-score als 'zeer grote fout' beschouwd. Een overzicht van het aantal mengmelkstalen per categorie binnen elke type CMT-test wordt weergegeven in Figuur 3.

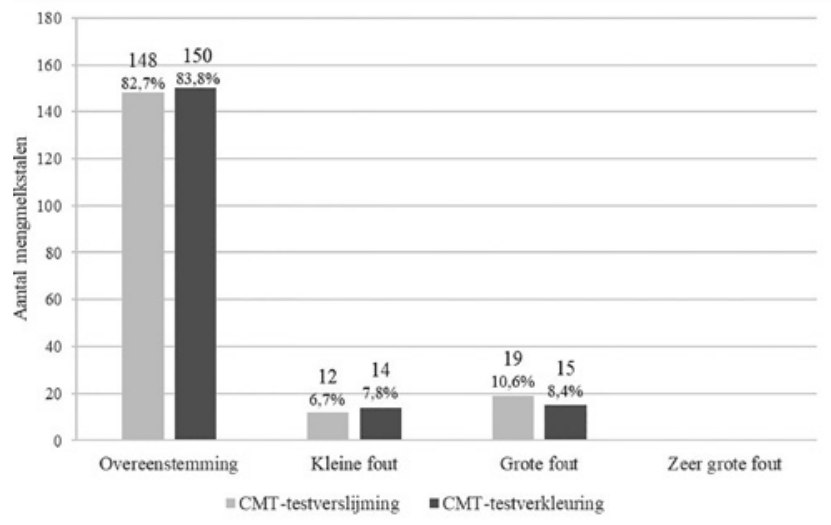

Figuur 3. Overzicht van het aantal mengmelkstalen (n = 179) per categorie van celgetal voor zowel de CMTtestverslijming als voor de CMT-testverkleuring. 


\section{Vergelijking testkarakteristieken California Mas- titis Test met elektronische celgetalbepaling}

\section{Elektronische celgetalbepaling}

De Se, Sp, PVW en NVW voor de detectie van een IMI met een minor en/of major pathogeen ten opzichte van niet-geïnfecteerde dieren bij een cut-off van 200.000 cellen $/ \mathrm{ml}$ bedroeg $44,4 \%$ (95\% BI 35,9$52,8 \%$ ), 72,2\% (95\% BI 51,5-92,9\%), 92,2\% (95\% BI $85,6-98,7 \%)$ en $14,9 \%$ (95\% BI 7,4-22,4\%), respectievelijk. Voor de detectie van een IMI met een major pathogeen ten opzichte van niet-geïnfecteerde dieren of dieren met een IMI veroorzaakt door een minor pathogeen bedroegen de Se, Sp, PVW en NV 65,5\% (95\% BI 52,8-78,0\%), 72,2\% (95\% BI 51,5-92,9\%), $87,8 \%$ (95\% BI 77,8-97,8\%) en 40,6\% (95\% BI 23,6$57,6 \%$ ), respectievelijk.

\section{California Mastitis Test}

Voor de CMT-testverslijming bedroeg de Se, Sp, PVW en NVW voor de detectie van een IMI met een minor en/of major pathogeen ten opzichte van nietgeïnfecteerde dieren bij een cut-off $\geq 142,9 \%$ (95\% BI 34,4-51,2\%), 66,7\% (95\% BI 44,9-88,4\%), 90,5\% (95\% BI 83,2-97,7\%) en $13,6 \%$ (95\% BI 6,5-20,8\%), respectievelijk en voor de CMT-testverkleuring $48,1 \%$ (95\% BI 39,6-56,6\%), 66,7\% (95\% BI 44,9$88,4 \%), 91,4 \%$ (95\% BI 84,8-97,9\%) en $14,8 \%(95 \%$ BI 7,1-22,5\%), respectievelijk. Voor de CMT-testverslijming bedroeg de Se, Sp, PVW en NVW voor de detectie van een IMI met een major pathogeen ten opzichte van niet-geïnfecteerde dieren of dieren met een IMI veroorzaakt door een minor pathogeen $69,1 \%$ (95\% BI 56,8-81,3\%), 66,7\% (95\% BI 44,9-88,4\%), $86,4 \%$ (95\% BI 76,2-96,5\%) en 41,4\% (95\% BI 23,4$59,3 \%$ ), respectievelijk en voor de CMT-testverkleuring $67,3 \%$ (95\% BI 54,8-79,6\%); 66,7\% (95\% BI $44,9-88,4 \%) ; 86,0 \%(95 \%$ BI $75,7-96,4 \%)$ en $40,0 \%$ (95\% BI 22,5-57,5\%), respectievelijk.

\section{DISCUSSIE}

In deze studie werden de testkarakteristieken van twee verschillende commercieel beschikbare CMTtesten onderzocht en vergeleken bij 179 mengmelkstalen van melkkoeien en dit in vergelijking met de elektronische celgetalbepaling. Bijkomend werd de distributie van de soorten mastitispathogenen aanwezig in de mengmelkstalen in kaart gebracht. In eerste instantie werden koeien geselecteerd met een verhoogd celgetal en nadien werd er aangevuld met dieren met een laag celgetal om in totaal per bedrijf zo een tiental koeien te kunnen bemonsteren.

De heterogene groep van NAS-species werd het frequentst geïsoleerd uit de mengmelkstalen. Deze bevinding komt overeen met de meest recente gegevens van MCC Vlaanderen (Melkcontrolecentrum
Vlaanderen, 2017), waar NAS in bijna $16 \%$ van de melkstalen van koeien met een verhoogd celgetal werden gevonden. Ook uit een voorgaande studie van de Onderzoekseenheid Mastitis \& Melkkwaliteit (Faculteit Diergeneeskunde, UGent), waarin meer dan 1080 cross-sectionele screenings werden uitgevoerd op Vlaamse melkveebedrijven bleken NAS het frequentst uit de melk geïsoleerd te worden (Piepers et al., 2007). Van de major pathogenen werd Streptococcus uberis (S. uberis) het vaakst geïsoleerd. In de literatuur wordt deze kiem veelvuldig geassocieerd met een sterke stijging van het celgetal (Bannerman et al., 2004). Uit de voorliggende studie bleek echter dat de kiem ook kan voorkomen bij dieren met een laag celgetal; S. uberis werd uit zes mengmelkstalen geïsoleerd van koeien met een celgetal $<200.000$ cellen $/ \mathrm{ml}$. Deze discrepantie in resultaten kan te wijten zijn aan verschillen in virulentie tussen de verschillende S. uberis-stammen (Tassi et al., 2013). Een andere verklaring kan gevonden worden in het feit dat het celgetal in de huidige studie bepaald werd bij een mengmelkstaal van de vier afzonderlijke kwartieren en er dus sprake is van een verdunningseffect met een onderschatting van het celgetal van het geïnfecteerde kwartier tot gevolg. Anderzijds kan ook een stijging van het aantal valsnegatieve resultaten voor het bacteriologisch onderzoek worden verwacht aangezien er mengmelkstalen afkomstig waren van koeien met een chronisch verhoogd celgetal en deze vaak geen kiemen meer uitscheiden in de melk.

Opmerkelijk is dat -op één uitzondering na- het gemiddelde, elektronisch bepaalde celgetal voor alle mengmelkstalen met eenzelfde CMT-score zowel voor de CMT-testverslijming als voor de CMT-testverkleuring, tussen de voorgestelde onder- en bovengrens lag. De bevindingen zijn in overeenstemming met de richtlijnen voorgesteld door Schalm en Noorlander bij de ontwikkeling van de CMT-test in 1957. Bij de evaluatie van de beide CMT-testen en de vergelijking ervan met de gouden standaard is gebleken dat van alle geanalyseerde mengmelkstalen in $82,7 \%$ en $83,8 \%$ van de gevallen het elektronisch bepaalde celgetal overeenstemde met het verwachtte celgetal op basis van de CMT-score bekomen via de CMTtestverslijming en de CMT-testverkleuring, respectievelijk. Voor beide testen bleef het percentage kleine fouten lager dan $10 \%$. Voor de CMT-testverslijming overschreed het percentage grote fouten net de grens van $10 \%$, wat niet het geval was bij de CMT-testverkleuring.

De Se van het elektronisch bepaalde celgetal om een IMI te identificeren met een major pathogeen dan met eender welke mastitiskiem was tot bijna $20 \%$ hoger. Deze bevinding is in overeenstemming met de resultaten van Jashari et al. (2016) en is vermoedelijk te wijten aan de lagere impact van de minor in vergelijking met de major pathogenen op het celgetal (Schukken et al., 2009). Echter, in vergelijking met de studie van Dohoo en Leslie (1991) waren de Se en $\mathrm{Sp}$ in de voorliggende studie bij een cut-off van 
$\geq 200.000$ cellen $/ \mathrm{ml}$ om een IMI met eender welke pathogeen of een major pathogeen te identificeren, opmerkelijk lager. Opnieuw kan het feit dat in deze studie werd gewerkt met meng- en niet met kwartiermelkstalen een belangrijke oorzaak van dit verschil zijn. Een overeenkomst met de studie van Dohoo en Leslie (1991) is dat de Se voor de identificatie van een IMI met een major pathogeen ook meer dan $10 \%$ hoger lag dan voor een IMI met een minor of major pathogeen.

Opmerkelijk is dat geen enkele van de testkarakteristieken van beide CMT-testen significant verschilde van deze bekomen voor de elektronische celgetalbepaling. Net zoals voor het elektronisch bepaalde celgetal en vermoedelijk om dezelfde reden was de Se bekomen in de voorliggende studie voor de identificatie van geïnfecteerde koeien via de CMT-test beduidend lager dan in andere studies. In de studie van Sargeant et al. (2001) werd met eenzelfde cutoff (CMT-score $\geq 1$ ) een Se bekomen van $56,7 \%$ om een kwartier te identificeren met een IMI veroorzaakt door eender welk pathogeen, tegenover een $\mathrm{Se}<50 \%$ voor de beide CMT-testen in de voorliggende studie. Sanford et al. (2006) vonden een Se van 70\% voor de detectie van een geïnfecteerd kwartier met eender welk pathogeen en een Se van $86 \%$ voor de detectie van een kwartier geïnfecteerd met een major pathogeen. In de huidigee studie was de $\mathrm{Se}<70 \%$ voor beide CMT-testen voor de identificatie van een IMI met een major pathogeen. De Sp bedroeg voor beide CMT-testen $66,7 \%$. In een recente studie uitgevoerd door Kandeel et al. (2018) bedroeg de Se $68 \%$ en de Sp 22\% bij een cut-off CMT-score $\geq 1$ voor de identificatie van een IMI met eender welk pathogeen.

Uit de bekomen resultaten kan worden geconcludeerd dat de celgetalbepaling met de CMT-test in dezelfde lijn ligt als het resultaat van een elektronische celgetalbepaling. De CMT-test kan dus gebruikt worden om koeien met een verhoogd celgetal, subklinische mastitis, op te sporen en zo te helpen bij de beslissing of het al dan niet nuttig is om melkstalen te nemen voor bacteriologisch onderzoek. Het verschil tussen de twee CMT-testen blijkt minimaal en dus kunnen ze beide gelijkwaardig in de praktijk worden ingezet.

\section{REFERENTIES}

Aghamohammadi, M., Haine, D., Kelton, D.F., Barkema, H.W., Hogeveen, H., Keefe, G.P., Dufour, S. (2018). Herd-level mastitis-associated costs on Canadian dairy farms. Frontiers in Veterinary Science 5, 100.

Bannerman, D.D., Paape, M.J., Goff, J.P., Kimura, K., Lippolis, J.D., Hope, J.C. (2004). Innate immune response to intramammary infection with Serratie mascescens and Streptococcus uberis. Veterinary Research 35, 681-700.

Barkema, H. W., Schykken, Y. H., Lam, T. J. G. M., Beiboer, M. L., Benedictus, G., Brand, A. (1999). Management practices associated with the incidence rate of clinical mastitis. Journal of Dairy Science 82(8), 1643-1654.
Blowey, R., Edmondson, P. (2010). Treatment and dry cow therapy. In: Mastitis control in dairy herds. Second edition, CABI Publishing, Wallingford, UK, pp. 202.

Boyen, F., Vangroenweghe, F., Butaye, P., De Graef, E., Castryck, F., Heylen, P., Vanrobaeys, M., Haesebrouck, F. (2010). Disk prediffusion is a reliable method for testing colistin susceptibility in porcine E. coli strains. Veterinary Microbiology 144, 359-362.

CRV, Coöperatieve Rundveeverbetering, (2019). Module MPR: Helder beeld van productie, gezondheid en dracht. - https://www.crv4all.be/service/module-mpr/ (laatst geconsulteerd op 21 januari 2019).

Dewulf, J., (2017). Diagnostiek. In: Een Inleiding tot de Veterinaire Epidemiologie. Acco, Leuven, België, pp. 71-82.

Dohoo, I.R., Leslie, K.E. (1991). Evaluation of changes in somatic cell counts as indicators of new intramammary infections. Preventive Veterinary Medicine 10, 225-237.

Halasa, T., Nielen, M., De Roos, A.P.W., Van Hoorne, R., de Jong, G., Lam, T.J.G.M., van Werven, T., Hogeveen, H. (2009). Production loss due to new subclinical mastitis in Dutch dairy cows estimated with a test-day model. Journal of Dairy Science 92, 599-606.

Harmon, R.J. (2001). Somatic cell counts: a primer. In: Proceedings of the Annual Meeting of the National Mastitis Council.

Heikkilä, A.M., Nousiainen J.L., Pyörälä S. (2012). Costs of clinical mastitis with special reference to premature culling. Journal of Dairy Science 95, 139-150.

Hogan, J.S., Gonzalez, R.N., Harmon, R.J., Nickerson, S.C., Oliver, S.P., Pankey, J.W., Smith, K.L. (1999). Somatic cell counts. In: Laboratory Handbook on Bovine Mastitis. Revised Edn. National Mastitis Council, WI, USA, pp. 157-171.

Hogeveen, H., Huijps, K., Lam, T.J.G.M. (2011). Economic aspects of mastitis: New developments. New Zeeland Veterinary Journal 59, 16-23.

Huijps, K., Lam, T. J., Hogeveen, H. (2008). Costs of mastitis: facts and perception. Journal of Dairy Science 75(1), 113-120.

Jashari, R., Piepers, S., De Vliegher, S. (2016). Evaluation of the composite milk somatic cell count as a predictor of intramammary infection in dairy cattle. Journal of Dairy Science 99, 9271-9286.

Kandeel, S.A.; Morin, D.E., Calloway, C.D., Constable, P.D. (2018). Association of California Mastitis Test scores with intramammary infection status in lactating dairy cows admitted to a veterinary teaching hospital. Journal of Veterinary Internal Medicine 32, 497-505.

Kivaria, F.M., Noordhuizen, J.P.T.M., Nielen, M. (2007). Interpretation of California mastitis test scores using Staphylococcus aureus culture results for screening of subclinical mastitis in low yielding smallholder dairy cows in the Dar es Salaam region of Tanzania. Preventive Veterinary Medicine 78, 274-285.

Melkcontrolecentrum Vlaanderen (2017). MCC Vlaanderen - http://www.mcc-vlaanderen.be/sites/default/files/ publicatiofiles/MCC_2017_JAARVERSLAG.pdf (laatst geconsulteerd op 27 augustus 2018).

National Mastitis Council (2004). National Mastitis Council: Procedure for collecting milk samples - http://www. nmconline.org/wp-content/uploads/2016/09/Proceduresfor-Collecting-Milk-Samples.pdf (laatst geconsulteerd op 8 augustus 2018).

Piepers, S., De Meulemeester, L., De Kruif, A., Opsomer, 
G. (2007). Prevalence and distribution of mastitis pathogens in subclinically infected dairy cows in Flanders, Belgium. Journal of Dairy Science 74, 478-483.

Rajala-Schultz, P.J., Gröhn, Y.T., McCulloch, C.E., Guard, C.L. (1999). Effects of clinical mastitis on milk yield in dairy cows. Journal of Dairy Science 82, 12131220.

Sanford, C.J., Keefe, G.P., Sanchez, J., Dingwell, R.T., Barkema, H.W., Leslie, K.E., Dohoo, I.R. (2006). Test characteristics from latent-class models of the California Mastitis Test. Preventive Veterinary Medicine 77, 96108.

Sargeant, J.M., Leslie, K.E., Shirley, J.E., Pulkrabek, B.J., Lim, G.H. (2001). Sensitivity and specificity of somatic cell count and California Mastitis Test for identifying intramammary infection in early lactation. Journal of Dairy Science 84, 2018-2024.

Schukken, Y.H., González R.N., Tikofsky, L.L., Schulte, H.F., Santisteban, C.G., Welcome, F.L. Bennett, G.J., Zurakowski, M.J., Zadoks R.N. (2009). CNS mastitis: nothing to worry about? Veterinary Microbiology 134, 9-14.
Tassi, R., McNeilly, T.N., Fitzpatrick, J.L., Fontaine, M.C., Reddick, D., Ramage, C., Lutton, M., Schukken, Y.H., Zadoks, R.N. (2013). Strain-specific pathogenicity of putative host-adapted and nonadapted strains of Streptococcus uberis in dairy cattle. Journal of Dairy Science 96, 5129-5145.

Van den Borne, B.H.P., Vernooij, J.C.M., Lupindu, A.M., van Schaik, G., Frankena, K., Lam, T.J.G.M., Nielen, M. (2011). Relationship between somatic cell count status and subsequent clinical mastitis in Dutch dairy cows. Preventive Veterinary Medicine 102, 265-273.

Vilt, Vlaams infocentrum land- en tuinbouw, (2017). Belgische rundvee- en varkensstapel gedaald in 2017. - http:// www.vilt.be/belgische-rundvee--en-varkensstapel-gedaald-in-2017 (laatst geconsulteerd op 14 mei 2018).

Zadoks, R.N., Middleton, J.R., McDougall, S., Schukken, Y.H. (2011). Molecular epidemiology of mastitis pathogens of dairy cattle and comparative relevance to humans. Journal of Mammary Gland Biology and Neoplasia 16, 357-372.

\section{VACATURE}

\section{Vakgroep Voortplanting, Verloskunde en Bedrijfsdiergeneeskunde}

Bij de Vakgroep Voortplanting, Verloskunde en Bedrijfsdiergeneeskunde van de Faculteit Diergeneeskunde (DI08), UGent is er een vacature beschikbaar voor het verrichten van onderzoek omtrent klauwverzorging bij melkvee.

Het betreft een onlangs toegewezen onderzoeksproject van $4(2 \times 2)$ jaar gefinancierd door Vlaio-LA (HBC.2018.2217), met als titel: "Innovatieve tools ter ondersteuning van preventieve en curatieve klauwverzorging bij melkvee".

Het betreft een samenwerking tussen de Vakgroep Voortplanting, Verloskunde en Bedrijfsdiergeneeskunde van de Faculteit Diergeneeskunde (DI08), het ILVO, Hogent, Inagro en de Hooibeekhoeve.

De taak van de kandidaat zal er in bestaan onderzoek te verrichten naar het effect van klauwverzorging op de klauwgezondheid van melkkoeien inclusief het gebruik van een aantal innovatieve tools. Het is de bedoeling dat de resultaten finaal resulteren in het behalen van een doctoraat. We zijn dus op zoek naar iemand die passioneel bezig wil zijn met de klauwverzorging van melkkoeien

Het project start tussen 1 oktober 2019 en 1 januari 2020. Deze vacature blijft open tot de positie is ingevuld.

Profiel: Masterin deDiergeneeskunde(bij voorkeuroptie herkauwers) ofMasterindeBio-ingenieurswetenschappen (met voldoende kennis en ervaring inzake klauwverzorging bij het rund).

Voor verdere informatie kunt $\mathrm{u}$ terecht bij:

Prof. Dr. G. Opsomer (09 26475 46)

Geert.opsomer@UGent.be 